\title{
National cord blood bank to recruit ethnic donors aggressively
}

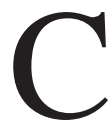

anada's new national cord blood bank plans to aggressively recruit donors who represent the country's diverse ethnic and multi-ethnic mix so as to increase the odds of ultimately providing stem cell matches to treat cancer patients with conditions such as leukemia and lymphoma.

Canadian Blood Services will model its recruitment strategy after one it has used in recent years to increase the diversity of bone marrow donors. The strategy primarily involves developing partnerships with communities and ethnic and demographic groups (including youths) to promote donations.

Canadian Blood Services also hopes that collecting umbilical cord blood within large inner-city hospitals, which serve an array of demographic groups, will promote the diversity of collections. The agency will start collecting umbilical cord blood at hospitals in Ottawa, Ontario, before branching out to Toronto, Ontario, Edmonton, Alberta, and Vancouver, British Columbia. In addition, it will forward kits that it hopes will enable nurses and other health care professionals in targeted areas, such as those with high numbers of Aboriginal births, to collect cord blood.

It is expected to take two years to establish the public cord blood bank, a \$36-million partnership among 12 provinces and territories (except Quebec) that must still raise $\$ 12$ million from private sources.

Expanding the diversity of the donor pool should dramatically increase the possibility that a Canadian patient in need of stem cells will find a match, says Sue Smith, executive director of stem cells for Canadian Blood Services. "We truly feel that this is going to be the game-changer that allows us to target the patients that we are unable to find a match for."

Canadians in need of stem cell donations now have access to stem cells derived from more than 17 million bone marrow donors (listed on 66 dif-

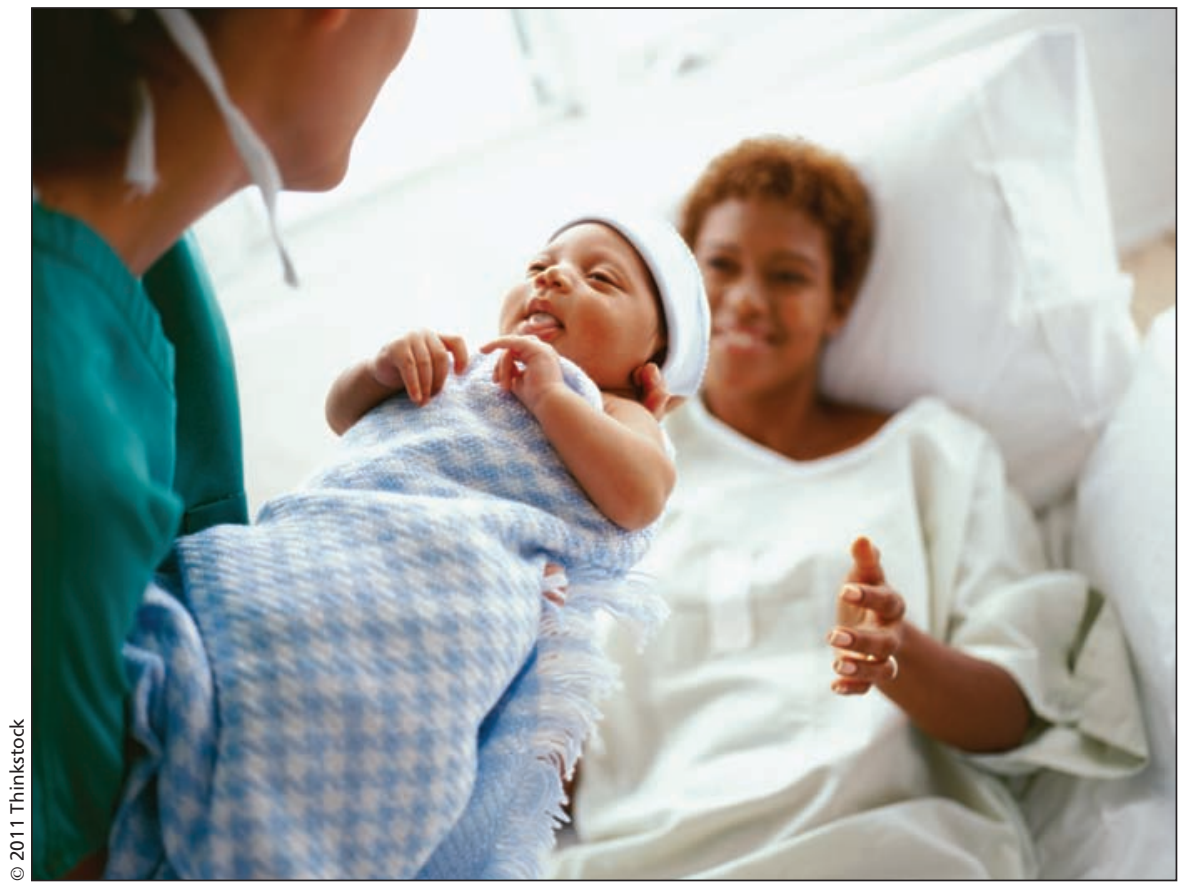

Canadian Blood Services' strategy to diversify its stores of umbilical cord blood involves developing partnerships with communities, and ethnic and demographic groups, to promote donations.

ferent registries worldwide) or those derived from 470000 cord blood units available through international registries. But even so, fewer than $60 \%$ of Canadians find matches.

Stem cells donors and recipients are matched using human leukocyte antigens (HLA) tissue typing. The hardest to match are those from unique populations such as Aboriginal peoples and those with multi-ethnic heritages, Smith says. "Because we are so ethnically diverse, we have marriages amongst diversities that cause even more of a challenge in matching, because multiethnic children are being born."

Cord blood is a critical source of stem cells because it is more tolerant of immune differences than are stem cells harvested from adult blood, says Dr. Donna Wall, director of Cancer Care Manitoba and the Manitoba Blood and Marrow Transplant Program at the University of Manitoba in Winnipeg.

"In cord blood transplantation we can use a donor who is a partial match, and that makes all the difference when we are trying to find donors for patients who have unusual HLA or immune types," Wall says.

The Manitoba transplant program is "frequently" in need of donors to match patients with challenging immune types, such as First Nations, Métis or Inuit people, Wall says.

Canadian Blood Services' strategy to increase the diversity of bone marrow donors altered the donor mix in the agency's OneMatch registry from $87 \%$ white and $13 \%$ other ethnicities to $80 \%-20 \%$ over a three-year period. "We have really moved that marker, through partnerships with the ethnically diverse leadership in communities," Smith says.

The agency also benefited by partnering with representatives of Canada's Chinese and South Asian communities, resulting in such initiatives as one which this year saw the OtherHalf Chinese Stem Cell initiative hold its third annual drive to collect cheek swab samples 
from donors at eight sites across Canada. They collected just under 6000 swabs in one-day clinics in Toronto, Vancouver and Calgary, Alberta.

"This is the main vehicle to deliver information about OneMatch and the need for more Chinese donors to match Canadian patients," says Susan Go, chair of the OtherHalf's board. The organization hopes to work with Canadian Blood Services on a program to promote umbilical cord blood donations.

'People weren't aware that there was such an urgent need, and also that it's tied to ethnicity," Go says.

In Quebec, the provincial blood agency Héma-Québec has been operat- ing a cord blood bank in collaboration with international registries for 18 months but there still is a pressing need for a broader donor pool that is more representative of the province's ethnic diversity, says Diane Roy, director of Stem Cell Donor Registry.

Thus far, Héma-Québec has provided cord blood for 15 transplants. In the interest of diversity, organizers have deliberately sought donations at hospitals serving the province's large Haitian population and other ethnic communities, Roy says. The agency collects cord blood at eight hospitals.

In Toronto, there remains a huge need for donors from Canada's Afro-
Canadian and Afro-American population, as well as from the South Asian communities, says Dr. John Doyle, head of the Blood and Bone Marrow Transplant section at The Hospital for Sick Children.

When approached, most women are happy to donate their children's umbilical cord blood, which is otherwise discarded, says Doyle, who uses cord blood cells primarily in transplants for children with leukemia. "I know that the cords are making a difference in our ability to do transplants." - Laura Eggertson, Ottawa, Ont.

CMAJ 2011. DOI:10.1503/cmaj.109-3885 